\title{
Research on the Teaching Reform of "Linear Algebra" Based on the Cultivation of Innovation Ability
}

\author{
Yanhong $\mathrm{Wu}$ \\ Basic teaching department \\ Shandong Huayu University of Technology \\ Shandong, China
}

\author{
Gaixia Wang* \\ School of Mathematics \& Physics \\ Anhui University of Technology \\ Anhui, China \\ Email:119934375@qq.com \\ *Corresponding author
}

\begin{abstract}
This paper mainly studies the teaching reform of "Linear algebra" course based on the cultivation of students' innovative ability, and the purpose of the paper is to carry out the reform of the course from three aspects: teaching content, teaching mode, examination and evaluation. In terms of teaching content, this paper mainly considers adding cases and corresponding math experiments. In terms of teaching mode, in terms of teaching mode, this paper builds a new teaching mode that is "theory + case + experiment, online + offline". This mode is suitable for teaching content and modern educational concept. In terms of assessment and evaluation, on the basis of the original assessment and evaluation, this paper adds the practice of quality development and mutual assessment of students, and the proportion structure of the assessment and evaluation content of each part is redetermined, which makes the assessment of students more objective and reasonable.
\end{abstract}

Keywords-basic courses; case set; teaching mode; evaluation

\section{INTRODUCTION}

"Linear Algebra" is an indispensable basic mathematics course for science and engineering majors and management majors in universities, and it is also a compulsory entrance examination for most postgraduate students. It not only provides essential basic knowledge for students to learn followup professional courses, but also can cultivate students' computing ability, logical reasoning ability and problemsolving ability. It plays an important role in the establishment of students' critical thinking. The traditional way of teaching is mainly teachers speaking and students listening. Students' learning enthusiasm and initiative are greatly restricted. In recent years, with the rapid development of informatization, educational informatization has become a hot direction of teaching reform[1-2]. Many colleges and universities have begun to explore the introduction of information means such as rain classroom and online course in the teaching of this course[3-5], and at the same time try to refine the process assessment in the aspect of assessment, so as to comprehensively evaluate the learning effect of students. However, at present, there are few studies on the teaching mode combining theoretical teaching, case teaching and experimental teaching, and the selection of evaluation

Project supported by the National Natural Science Foundation of China (No.11601005) and Educational teaching and new engineering research project of 2018 of Shandong Huayu University of Technology (No.2018XGK01) indicators, evaluation factors and weight ratio of assessment needs to be further studied. Fig. 1 shows the design idea of the whole research process.

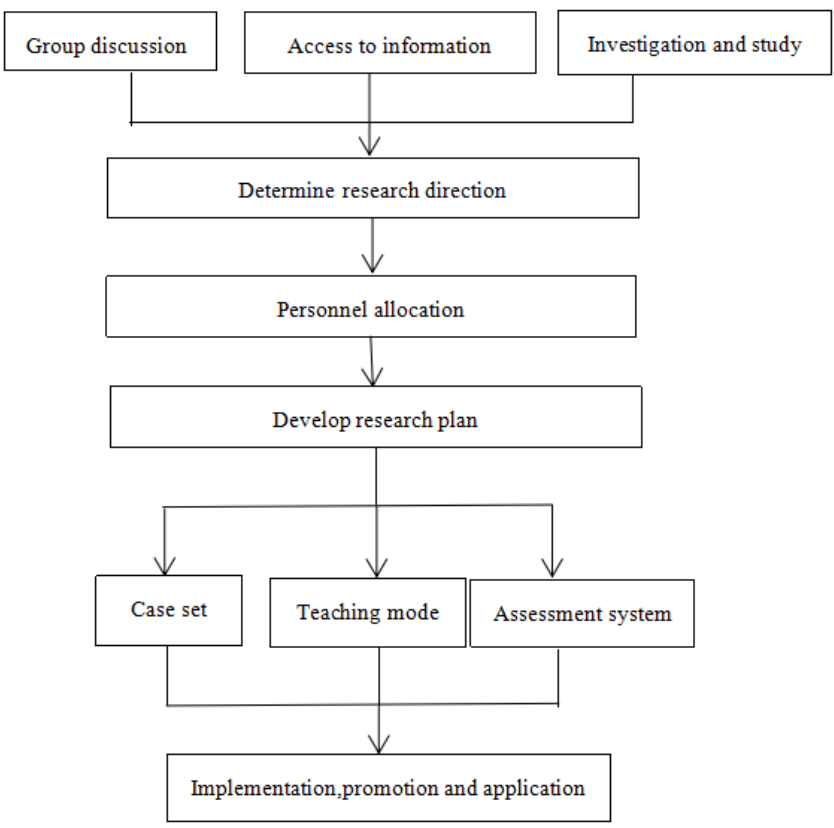

Fig.1. Research idea

\section{THE DIALECTICAL UNITY RELATIONSHIP BETWEEN COLLEGE STUDENTS' INNOVATION ABILITY AND LINEAR ALGEBRA CURRICULUM REFORM}

Innovation is the driving force of development, and things will stand still without innovation. Today's society is changing rapidly and developing at an astonishing speed. As college students who are about to enter the society, if they do not have certain innovation ability, it is difficult to get a foothold in the society, and they will not have better development. As a public basic course, mathematics plays an extremely important role in the cultivation of students' innovative ability, especially in the cultivation of students' critical thinking and logical thinking. Students in professional learning, if with the help of mathematical knowledge, can be more in-depth study of 
professional knowledge. As an important course in university mathematics system, linear algebra plays an important role in cultivating students' ability of calculation, logical thinking and practical application, which is an indispensable part of innovation ability. Therefore, the reform of "linear algebra" course is to make it more suitable for modern education and more in line with the concept of college students' ability cultivation.

\section{BUILD AN INNOVATIVE FACULTY}

Since ancient times, there has been such a saying. The role of a teacher is to preach, impart knowledge and solve problems. Teachers play a decisive role in the knowledge construction and ability cultivation of students. If teachers want to teach students with innovative ability, they must have very strong innovative ability. In this "linear algebra" curriculum teaching reform, a very important aspect is to create a team of teachers with innovative spirit, innovative ability, only the teachers have the ability to innovate, will teach the knowledge as open, rather than let students learn the book knowledge. Only teachers can consciously and purposefully guide students to think about problems from different aspects. For example, when teaching matrix, teachers should not only give the concept of matrix, so that students cannot connect it with daily life and professional study. Teachers can combine all aspects in daily life use indicator, case, let the students discuss thinking, thereby introducing concept of matrix, and the matrix to study these examples, so that students can abstract embodiment of knowledge, to understand the knowledge visualization, more can let students understand mathematics is ubiquitous, omnipotent. At the same time, in the process of students talking and thinking, all kinds of innovation-related abilities can be enhanced.

\section{FORM A CASE SET WHICH IS SUITABLE FOR TEACHING "LINEAR ALGEBRA”}

"Linear algebra" is a general education course for undergraduate majors in universities. It mainly introduces the related knowledge of matrix, which is an important means to discretize the continuity problem and an indispensable tool to solve the optimization problem. It has a wide range of applications in all aspects of real life. In order to fully cultivate students' ability of application and innovation, cases related to matrix and equations in real life and professional application can be collected to form a case set, so as to enrich the teaching content of this course and make students feel useful. On the one hand, the selection of cases should be highly relevant to the given knowledge, and should be easy to understand, and the actual life of students or professional knowledge has a strong correlation, to have practical, and interesting, can arouse the interest of students to discuss, so as to achieve good teaching effect. Such as: Financial companies can be introduced to students majoring in economic management payment fund flow problems, input-output problems and other cases; Electronic information engineering, electrical engineering students can introduce flat plate stability state temperature distribution problem, circuit design problem and other cases; Traffic flow analysis is introduced to traffic engineering students questions and other cases.

\section{Construct a Teaching Mode That Is "Theory + CAse + EXPERIMENT, ONLINE + OFFLINE"}

First of all, the designed cases are combined with theoretical knowledge to be introduced into the classroom. On the one hand, the enthusiasm of students to participate in classroom learning is enhanced; on the other hand, the learned knowledge is made vivid, so that it does not stay at the abstract and incomprehensible mathematical knowledge. Through the teaching mode of case introduction -- case discussion -- new knowledge explanation -- case solution, students can truly understand the value of this course. At the same time because of the course "linear algebra" large amount of calculation and tedious calculation process results error-prone, can through experiment, to some of the large amount of calculation of knowledge in the interpretation of the results by Matlab experiments at the same time[6-9], to verify the correctness of the result, is more advantageous to the students master the software to solve practical problems. Secondly, with the development of modern information technology, educational informatization has gradually become an irresistible trend, which can greatly improve the efficiency of teaching and make education in line with the development of The Times. In order to relieve the pressure on lesson little bring to this course, can use the information means, will be more difficult to understand the "linear algebra" knowledge into a small video, it and prepare knowledge, selected cases in time through the rain or intelligence to students during class, let the student through self-study + mentoring approach to learning, and master the knowledge.

Take matrix multiplication as an example to introduce the whole teaching process. Before class, the teacher will send the preview courseware and cases to the students through rain class or smart class APP, so that the students can have a preliminary understanding of the learning knowledge and the cases to be solved in class. For example, when teaching matrix multiplication, the teacher can first send the following cases to the students. Given the prices of three fruits in two stores, the number of fruits needed by two people and the number of two people in two towns, the matrix is as follows.

$$
\begin{aligned}
& \text { storeA storeB } \\
& \underset{\text { pear }}{\text { apple }}\left[\begin{array}{cc}
0.10 & 0.15 \\
0.15 & 0.20 \\
0.10 & 0.10
\end{array}\right] \quad \text { peopleA } \quad\left[\begin{array}{ccc}
5 & 10 & 3 \\
4 & 5 & 5
\end{array}\right] \\
& \text { peoplea peopleB } \\
& \text { town1 }\left[\begin{array}{ll}
1000 & 500 \\
2000 & 1000
\end{array}\right]
\end{aligned}
$$

Let's call the first matrix $A$, the second matrix $B$, and the third matrix $C$.

(1) What is the cost of fruit per person per store?

(2) How much each fruit should be bought in each town?

In class, students are divided into groups first, and each group of students will discuss the case collectively. Each group of students will use the knowledge they have learned to solve the case. When the discussion process is over, representatives from each group will make a summary of the discussion process. When the students feel unable to solve the case with 
the knowledge they have learned, the teacher starts to explain the concept and calculation of matrix multiplication and other relevant knowledge, and then leads the students to associate the case with the knowledge they have learned, so that the students can think about whether they can use matrix multiplication to solve the problem. After solving the case, the teacher can further guide the students to discover various operation rules of matrix multiplication through the case. When the students fully master the new knowledge, the teacher can lead the students to the next knowledge point--the application of matrix multiplication. This is a good time for students to move on to the second case.

The stationery sold by a stationery store in a week is shown in the following table. The weekend inventory and closing accounts are used to calculate the daily sales revenue of the store and the weekly sales ledger.

TABLE I. SALES VOLUME AND UNIT PRICE OF STATIONERIES

\begin{tabular}{|c|c|c|c|c|c|c|c|}
\hline \multirow{2}{*}{ Stationery } & \multicolumn{6}{|c|}{ Week } & Unit Price \\
\cline { 2 - 8 } & Monday & Tuesday & Wednesday & Thursday & Friday & Saturday & \\
\hline Rubber & 15 & 8 & 5 & 1 & 12 & 20 & 0.3 \\
\hline Ruler & 15 & 20 & 18 & 16 & 8 & 25 & 0.5 \\
\hline Glue & 20 & 0 & 12 & 15 & 4 & 3 & 1 \\
\hline
\end{tabular}

Let students use the learning knowledge to solve this case independently, in order to achieve the purpose of consolidating knowledge. Because the difficulty of this part of knowledge is the large amount of calculation, students often makes mistakes in the process of doing the problem, so on the basis of hand calculation, students can use Matlab learning to solve problems, so as to improve students' ability to solve practical problems and operational ability.

\section{ESTABLISH A TWO - DIMENSIONAL COMPREHENSIVE ASSESSMENT SYSTEM}

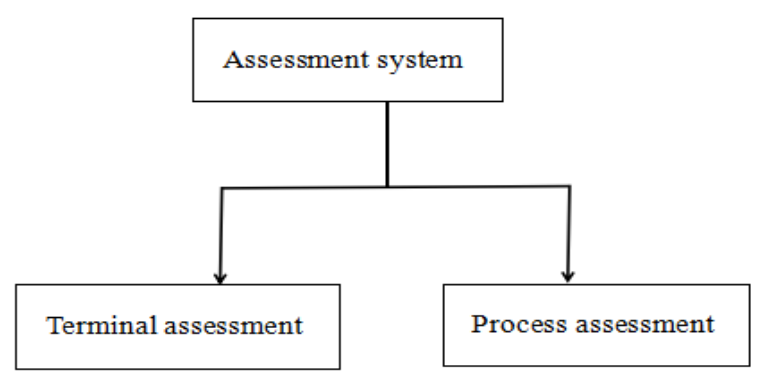

The purpose of assessment and evaluation is to evaluate the teaching result of teachers and the learning effect of students in order to find out the problems existing in the process of teachers' teaching and students' learning so as to better implement teaching activities. For the course of "Linear Algebra", the horizontal dimension divides the evaluation system into two parts, the process assessment and the terminal assessment. The vertical dimension further refines the process assessment and adjusts the proportion of each part. The terminal evaluation is mainly presented in the form of the final examination. When designing the final examination paper, the topic should be selected strictly according to the difficulty ratio of the questions. The examination of knowledge points should be comprehensive and the practicability of the course should be highlighted. In the examination, the emphasis on process assessment. In the past, the process assessment was mainly about attendance, daily work, mid-term test, classroom performance and other aspects. The reform of "linear algebra" course is characterized by its application. Therefore, on the basis of the original assessment and evaluation, it is necessary to increase the quality development and practical homework, so that students can solve the corresponding practical problems through the learned knowledge and the models and procedures learned in experimental classes, so as to improve students' ability to solve practical problems, which is also one of the concrete manifestations of the improvement of students' innovation ability. At the same time, in order to make the evaluation fair, students' mutual evaluation is added on the basis of the original evaluation system. On the other hand, due to the increase of evaluation content, this reform also adjusted the proportion of each evaluation content. The two-dimensional assessment system is shown in Fig. 2.
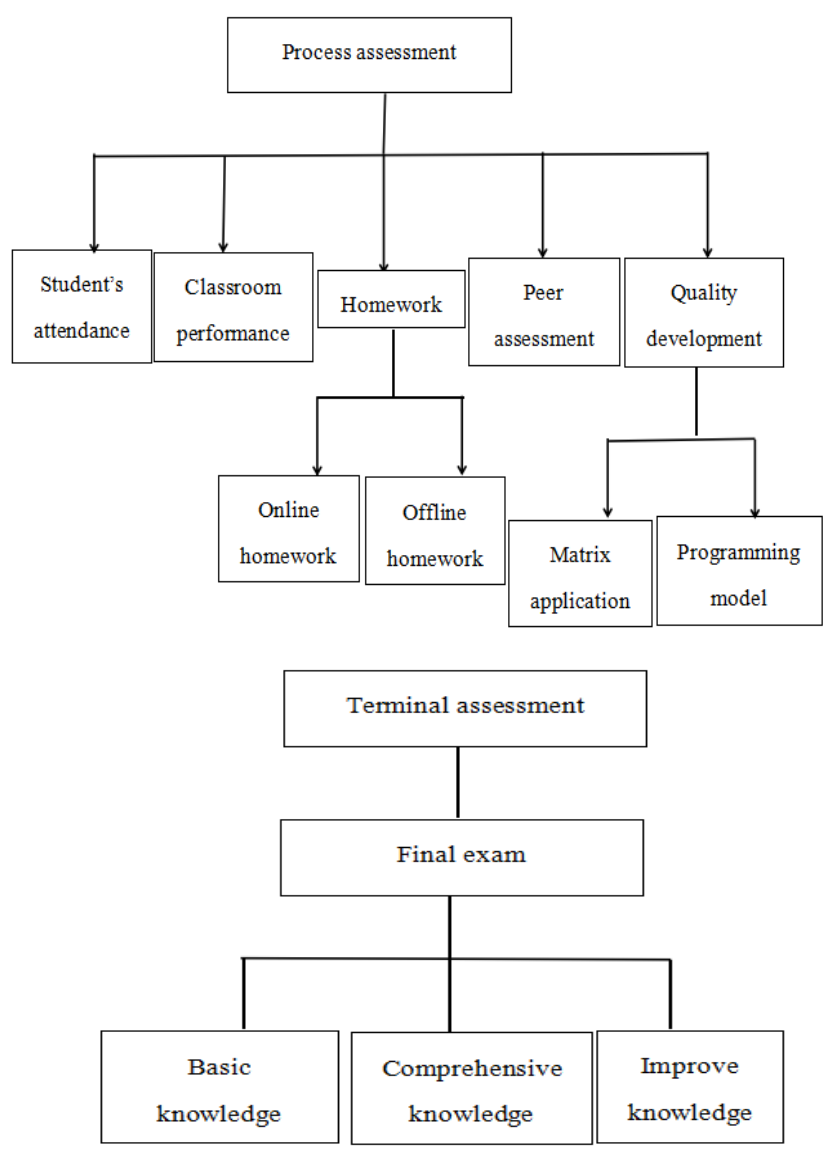

Fig.2. Assessment system 


\section{CONCLUSION}

The innovation ability of students determines the breadth and depth of future development in professional fields. As an important place to cultivate students' innovation ability, universities should choose appropriate content, methods and assessment methods in each course teaching if they want to truly fulfill the mission of cultivating students' innovation ability.

This article mainly aims at the reform of the "linear algebra" , and it studies the reform of various aspects in order to adapt to the cultivation of students' innovative ability, which is mainly reflected in three aspects of the teaching process. Firstly, according to the teaching content, on the basis of the original book teaching content, a set of case sets suitable for the teaching of "linear algebra" course are studied and sorted out. The case set contains typical cases related to the content of each chapter of "linear algebra" course, including cases in real life and cases related to students' majors. For example, students majoring in economic management will choose some economic cases, electrical engineering and automation major and electronic information major, and choose some cases related to electricity. Through the integration of cases and original teaching content, the course of "linear algebra" is closer to students' reality, so that students can love learning and enjoy learning. Secondly, in view of the reform of teaching content, the case teaching method and experiment teaching method are selected to adapt to the teaching content and modern educational concept. On the one hand, the selected cases can be integrated into the teaching process, so that students can learn new knowledge in the process of discussing methods to solve cases, which increases the practicability of this abstract course and improves students' ability to solve practical problems. For this course, on the other hand, large amount of calculation and the application in the planning problem, design some mathematical experiment is very necessary, also is the trend of The Times, through the experiment of the course exercise, students' practical operating ability, ability to solve practical problems will further strengthen, will lay a solid foundation for some technology competition. Finally, in view of the research contents and research methods, pattern reform, make the corresponding adjustment on the inspection way, increased the quality development and practice, and case teaching and experimental teaching photograph echo, with increased students' mutual, to ensure the fairness of the process of evaluation, in adjusting the assessment content and assessment on the proportion of the parts made a corresponding adjustment, highlight the practical application. In this way, the three aspects form a complete loop.

The course teaching reform is a complicated work, which should be different according to The Times. With the continuous improvement of modern means, the pace of reform cannot be stopped, but the purpose of reform will never change, which is to make mathematics more closely follow the pace of The Times and better serve students and the society.

\section{ACKNOWLEDGMENT}

Thanks for the "National Natural Science Foundation of China (No.11601005)" and "Educational Teaching and New Engineering Research Project of 2018 of Shandong Huayu University of Technology (No.2018XGK01)”

\section{REFERENCES}

[1] Li Qinghua. Exploration on the effective integration of mathematical modeling into linear algebra teaching $[\mathrm{J}]$. Education modernization. 2018(39). (In Chinese)

[2] Liu Chunying. Reflections on the reform of linear algebra teaching [J]. Science and technology vision. 2018(35). (In Chinese)

[3] Fang Jiating. Research on teaching reform of linear algebra in application-oriented undergraduate universities [J]. Chinese and foreign entrepreneurs. 2018(30). (In Chinese)

[4] Wan Bingrong, Li Xiaoling. Discussion on teaching reform of linear algebra course using mathematical software [J]. Journal of Chifeng University (Natural science edition). 2013(07). (In Chinese)

[5] Wang Zhihua. Some measures of linear algebra teaching reform in application-oriented undergraduate colleges [J]. Journal of Jilin University of ducation. 2018(11). (In Chinese)

[6] Tian Renbi. Teaching reform of linear algebra course and strengthening training of applied talents [J]. Asia-pacific education. 2016(22). (In Chinese)

[7] Li Qinghua. Exploration on teaching reform of "linear algebra" in application-oriented universities [J]. New curriculum research (midmonth issue). 2018(01). (In Chinese)

[8] Liu Lihong, Chen Guangzu. Discussion on the teaching reform of "linear algebra" course in undergraduate institutions under the credit system [J].Intelligence. 2018(07). (In Chinese)

[9] Shi Jing. Research on teaching reform of linear algebra in applicationoriented undergraduate universities [J]. Fujian Computer. 2018(09). (In Chinese) 